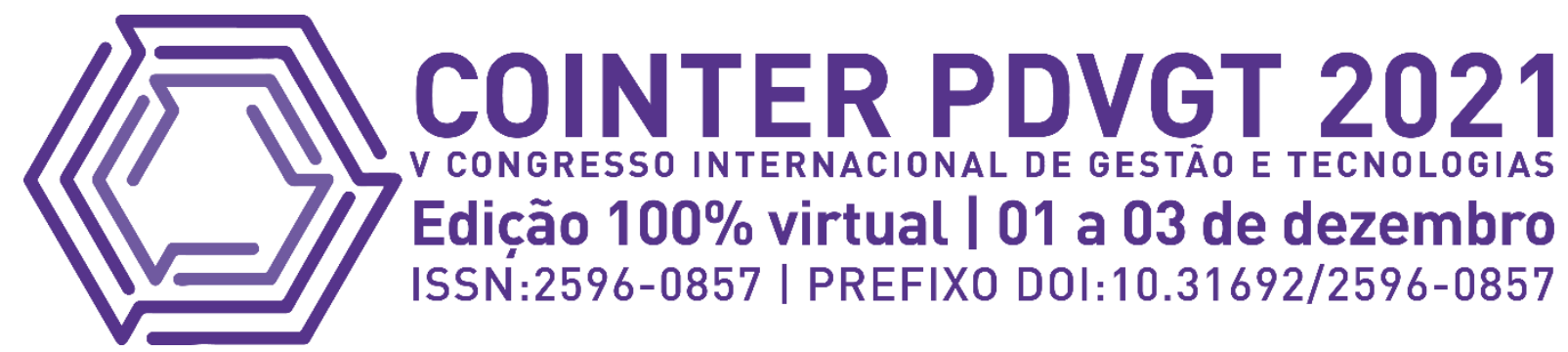

\title{
ANÁLISE DO PERFIL DOS ESTUDANTES PROTAGONISTAS DAS AÇÕES DO PROGRAMA INTERNACIONAL DESPERTANDO VOCAÇÕES NO IFPE - CAMPUS VITÓRIA DE SANTO ANTÃO
}

\section{ANÁLISIS DEL PERFIL DE ESTUDANTES PROTAGONISTAS EN LAS ACCIONES DEL PROGRAMA INTERNACIONAL DESPERTANDO VOCACIONES EN IFPE - CAMPUS VITÓRIA DE SANTO ANTÃO}

\section{ANALYSIS OF THE PROFILE OF STUDENTS PROTAGONISTS IN THE ACTIONS OF THE INTERNATIONAL PROGRAM AWAKENING VOCATIONS AT IFPE - VITÓRIA DE SANTO ANTÃO CAMPUS}

\author{
Apresentação: Comunicação Oral \\ Sabrina Kelly Andrade de Oliveira ${ }^{1}$; Renata Cristine de Sá Pedrosa Dantas ${ }^{2}$
}

DOI: https://doi.org/10.31692/2596-0857.VCOINTERPDVGT.0022

\section{RESUMO}

Esta pesquisa teve por objetivo analisar os perfis dos estudantes protagonistas de ações do Programa Internacional Despertando Vocações no Instituto Federal de Pernambuco, Campus Vitória de Santo Antão, com a finalidade de elucidar a compreensão das mudanças organizacionais, permitindo visualizar de que forma os processos de habitualização, tipificação, objetificação e exteriorização se formam e influenciam no isomorfismo institucional. Para assim colaborar com o entendimento sobre formação empreendedora, protagonismo estudantil e mudanças organizacionais em instituições de ensino brasileiras através de uma exígua amostragem retirada dos programas PDVL (Programa Internacional Despertando Vocações para Licenciatura) e PDVAgro (Programa Internacional Despertando Vocações para Ciências Agrárias). Para a obtenção de dados foi aplicado um questionário com a finalidade de coletar uma amostragem dos participantes do PDVL e do PDVAgro. No total, o questionário obteve 32 respostas de participantes dos programas estudados, sendo 47\% do PDVL e 53\% do PDVAgro. Os resultados foram dispostos em Gráfico analisados. Com a análise dos dados obtidos foi possível constatar que a participação nos programas propiciou aos alunos o afloramento do

\footnotetext{
1 Licencianda em química, Instituto Federal de Pernambuco - Campus Vitória de Santo Antão, sabrinak10319@gmail.com

${ }^{2}$ Doutora em Ciência da Computação pelo Centro de Informática/UFPE, Professora do Instituto Federal de Pernambuco - Campus Recife, renatadantas@ recife.ifpe.edu.br
} 
protagonismo, bem como as características empreendedoras descritas por Dornelas (2008). Segundo frases e palavras citadas pelos pesquisados, é notório a contribuição dos programas no incentivo ao trabalho em grupo e o quão essas ações auxiliam no desenvolvimento pessoais e profissionais dos mesmos. Fator reforçado pela tendência dos respondentes em continuarem no programa durante todo período acadêmico. O IIDV (Instituto Internacional Despertando Vocações) - instituição responsável pelos programas - juntamente com o IFPE tem por princípios a democratização do ensino e o cooperativismo, e estes podem ser alavancados pelo desenvolvimento do Protagonismo e pela formação empreendedora, desenvolvida no âmbito do PDV.

Palavras-Chave: Protagonismo estudantil, empreendedorismo jovem, educação empreendedora

\section{ABSTRACT}

This research aimed to analyze the profiles of students who are protagonists of actions of the International Program Awakening Vocations at the Federal Institute of Pernambuco, Campus Vitória de Santo Antão, in order to elucidate the understanding of organizational changes, allowing to visualize how the processes of habituation, typification, objectification and exteriorization form and influence institutional isomorphism. In order to collaborate with the understanding of entrepreneurial training, student protagonism and organizational changes in Brazilian educational institutions through a small sample taken from the PDVL (International Program Awakening Vocations for Licentiate) and PDVAgro (International Program Awakening Vocations for Agricultural Sciences) programs. To obtain data, a questionnaire was applied in order to collect a sample of the participants of the PDVL and PDVAgro. In total, the questionnaire received 32 responses from participants in the programs studied, 47\% from PDVL and 53\% from PDVAgro. The results were displayed in an analyzed graph. With the analysis of the obtained data, it was possible to verify that the participation in the programs provided the students with the emergence of protagonism, as well as the entrepreneurial characteristics described by Dornelas (2008). According to phrases and words cited by respondents, the contribution of programs in encouraging group work and how these actions help in their personal and professional development is notorious. Factor reinforced by the tendency of respondents to continue in the program throughout the academic period. The IIDV (International Awakening Vocations Institute) - the institution responsible for the programs - together with the IFPE has as its principles the democratization of education and cooperativism, and these can be leveraged by the development of Protagonism and entrepreneurial training, developed within the scope of the PDV.

Keywords: Student protagonism, youth entrepreneurship, entrepreneurial education

\section{INTRODUÇÃO}

A presente pesquisa visa colaborar, através dos seus resultados, com o entendimento do perfil dos estudantes que protagonizam ações no PDV. O protagonismo, juntamente ao empreendedorismo, vem sendo discutido e incentivado com diligência nas últimas décadas. 
Estudos mostram que o protagonismo e empreendedorismo são "ensinados" ou "aflorado" ao individuo, sendo observadas por padrões socias comuns, o isomorfismo institucional busca elucidar a homogeneidade das organizações trazendo clareza da importância do conhecimento dos padrões que rodeiam uma empresa para potencializar ou impossibilitar mudanças par sua melhoria (DIMAGGIO E POWELL, 1983).

A participação em programas de pesquisa e extensão colaboram para o desenvolvimento pessoal e social, aproximando o estudante da sociedade e construindo, através da experiência, transformações no individuo, que vão além de suas ações em sala de aula. Como revelado em pesquisas a participação em ações de pesquisa e extensão aumenta a empatia do participante bem como seu protagonismo, tendo em vista que estarão a frente do projeto assumindo responsabilidades.

Dornelas (2008) em seu livro "empreendedorismo transformando ideias em negócios" cita características que um empreendedor precisa ter bem desenvolvidas para obter sucesso. Tais características norteam as análises feitas durante a pesquisa, sob hipótese de que o comportamento protagonista e empreendedor poder ser reforçado e até descoberto com a participação em programas voltados a ações extensionistas e de pesquisa.

O Programa Internacional Despertando Vocações (PDV) tem por faculdade o estímulo a inovação, a produção cultural, o empreendedorismo, o cooperativismo e o desenvolvimento científico, através do ambiente de troca de saberes e fazeres entre os professores, colaboradores voluntários e estudantes (IIDV, 2018). O Instituto Federal e Pernambuco - IFPE - tem buscado cumprir sua missão de promover ações de ensino, pesquisa e extensão, comprometida com uma prática cidadã e inclusiva, de modo a contribuir para a formação do ser humano e o desenvolvimento sustentável da sociedade (IFPE, 2016).

Esta pesquisa tem como objetivo geral a análise do perfil dos estudantes protagonistas das ações do Programa Internacional Despertando Vocações no IFPE- Campus Vitória Santo Antão.

Os objetivos específicos foram definidos de modo que conduzissem o trabalho para o alcance do objetivo geral. São eles: realizar o mapeamento dos estudantes que protagonizam ações no Programa Internacional Despertando Vocações - PDV - no IFPE campus Vitória de Santo Antão, identificar as atividades pelas categorias: estudantes e egressos, analisar o perfil dos participantes protagonistas das ações.

\section{FUNDAMENTAÇÃO TEÓRICA}

Segundo Dornelas (2008, p. 12) com as "várias tentativas de estabilização da economia 
e da imposição advinda do fenômeno da globalização, muitas grandes empresas brasileiras tiveram de procurar alternativas para aumentar a competitividade, reduzir os custos e manterse no mercado." Trouxe por consequência uma alta no desemprego, e os ex-funcionários, por falta de alternativas, munidos de suas economias pessoais e fundo de garantia, mesmo por vezes sem experiência no ramo, decidem abrir seus próprios negócios, tornando-se agora patrões.

Essa conjunção de fatores somados despertou discussões a respeito do tema empreendedorismo no país, com crescente ênfase para pesquisas relacionadas ao assunto no meio acadêmico e também com a criação de programas específicos voltados ao público empreendedor (DORNELAS, 2008, p.22).

As universidades, escolas secundárias e outras instituições de ensino devem trabalhar em conjunto para promover o desenvolvimento do empreendedorismo nas etapas de formação (SARKAR, 2014, p.83).

Para Teixeira et. al. (2011), fatores que venham a influenciar escolhas, ações e comportamentos do jovem empreendedor são importantes para entender as motivações destes e para compreender como ocorre o processo empreendedor. Nesta perspectiva, afirmam de Oliveira Lima-Filho, Sproesser e Martins (2009), que é imprescindível apresentar aos jovens e também aos setores econômicos do Brasil que existem alternativas de inclusão econômica acessível a todos. E assim, seja possível romper com o pensamento tradicionalista de que o emprego formal constitui a única forma de ocupação profissional (BRASIL, 2013 p.2).

Na visão da BNCC (2018), protagonismo estudantil tem dupla face entrelaçada: serve para que os estudantes, ancorados em motivação intrínseca (NORTON, 2016, PINK, 2009), aprendam como autores; e serve para que avancem em sua formação socioemocional como pessoas e cidadãos (DEMO, 2020 p. 3).

Nesse sentido, visando a uma educação sólida e aberta, não se aceitam discriminações; promovem-se a riqueza e a diversidade dos talentos individuais e expande-se o perímetro da própria sala de aula a cada âmbito da experiência social em que a educação pode gerar solidariedade, partilha e comunhão (BARBOSA, 2017 p. 5).

Segundo Carvalho (2014) a energia da inovação é liberada principalmente no processo do aprender em grupo. Dessa forma, o aprendizado organizacional representa tarefas coletivas que agregam qualidades aos relacionamentos.

Dessa forma, é possível inferir que troca de conhecimentos e experiências entre indivíduos no desenvolvimento de ações em programas de extenção e pesquisa, contribuam no despertamento do protagonismo e empreendedorismo nos participantes dos programas. 


\section{METODOLOGIA}

Foi desenvolvida uma pesquisa aplicada que segundo Prodanov e Freitas (2013, p. 51) são pesquisas que têm por "objetivo gerar conhecimentos para aplicação prática dirigidos à solução de problemas específicos. Envolve verdades e interesses locais." A pesquisa é de natureza quantitativa, que ainda segundo Prodanov e Freitas (2013, p. 69) são aquelas que considera tudo que se pode ser quantificado, ou seja, representação de informações e opiniões em números, para poder classificá-las e analisá-las, e qualitativa, que de acordo com Minayo (2002, p. 22) é abordagem que "aprofunda-se no mundo dos significados das ações e relações humanas." Sob abordagem descritiva que de acordo com Gil (2010, p. 28) são aquelas que têm por “objetivo primordial a descrição das características de determinada população ou fenômeno ou estabelecimento de relações entre variáveis." Os sujeitos de pesquisa foram os pessoas que atuam ou atuaram no Programa Despertando Vocações (PDV) no IFPE - Campus Vitória de Santo Antão.

Para a obtenção de dados foi aplicado um questionário com a finalidade de coletar uma amostragem dos participantes do Programa Despertando Vocações para Licenciatura (PDVL) e do Programa Despertando Vocações para Ciências agrárias (PDVAgro). Inicialmente o questionário foi aplicado entre os dias 13/04/2021 e 31/05/2021, no entanto com o intuito de aumentar a quantidade de respondentes, o período de aplicação foi estendido até o dia 09/06/2021. No total, o questionário obteve 32 respostas de participantes dos programas estudados. Os resultados do questionário serão analisados a seguir.

\section{RESULTADOS E DISCUSSÃO}

Foi aplicado um questionário aos estudantes e egressos que atuam/atuaram no Programa Internacional Despertando Vocações (PDV) nos programas Despertando Vocações para Licenciatura (PDVL) e Despertando Vocações para Ciências agrárias (PDVAgro) do IFPE Campus Vitória de Santo Antão.

As primeiras questões do formulário foram elaboradas para análise do perfil dos estudantes. Dentre elas estão questões acerca da faixa etária, sexo, modalidade de ensino, programa ligado, entre outras. Dos estudantes respondentes, $44 \%$ têm entre 17 e 20 anos, 34\% entre 21 e 24 anos e $13 \%$ entre 25 e 28 e $9 \%$ acima de 28 anos (Gráfico 1). Os dados obtidos sobre a faixa etária demonstram uma forte presença dos jovens das idades iniciais da juventude presentes nas ações, o que segundo Global Entrepreneurship Monitor (GEM, 2015) uma das mais importantes pesquisas relacionadas a empreendedorismo, o brasil apresenta a mais elevada taxa de empreendedores iniciais com faixa etária de 18 a 24 anos, e que podem estar 
frequentando ensino superior, tendo em vista que nessa faixa etária encontra-se maior contingente de universitários.

Gráfico 1: idade dos respondentes

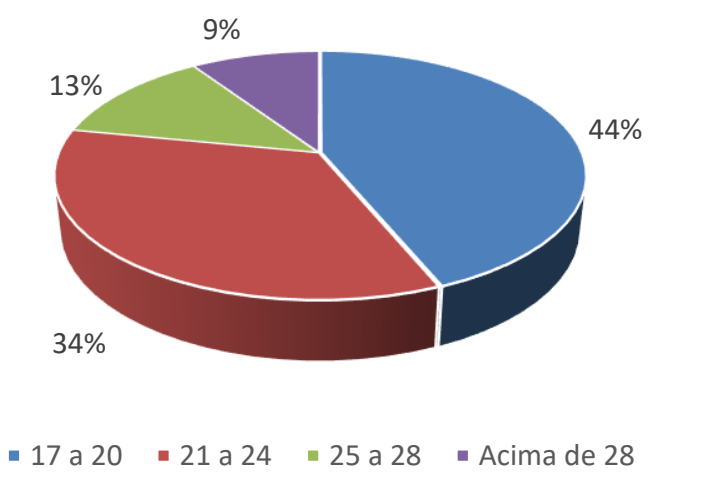

Fonte: Própria (2021)

De acordo com o GEM de 2015 sobre o empreendedorismo no Brasil existe uma igualdade de gênero nos empreendedores iniciais brasileiro tendo em média 21,7\% de homens e 20,3\% de mulheres (dados do GEM, 2015, p.37). Na amostragem houve uma atenuação das respondentes do sexo feminino, aproximadamente $38 \%$ são do sexo feminino e $62 \%$ dos estudantes são do sexo masculino (Gráfico 2). Isso pode ser causado pela predominância dos cursos na área agrária dos respondentes, observados nos participantes ligados ao PDVAgro (53\%) em detrimento aos ligados ao PDVL (47\%) (Gráfico 3), e ainda na modalidade de ensino categorizado por $44 \%$ do curso de agronomia, $3 \%$ do curso integrado agropecuária, $3 \%$ do curso subsequente em zootecnia.

Gráfico 2: Sexo dos respondentes

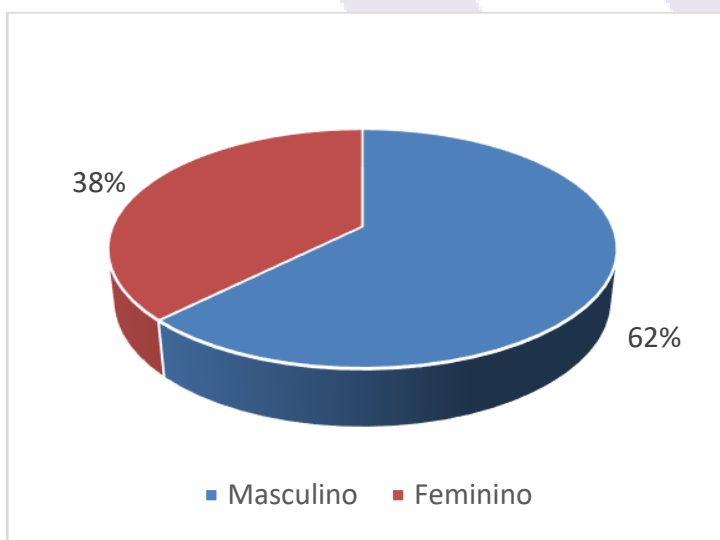

Fonte: Própria (2021)
Gráfico 3: Programa ligado aos respondentes

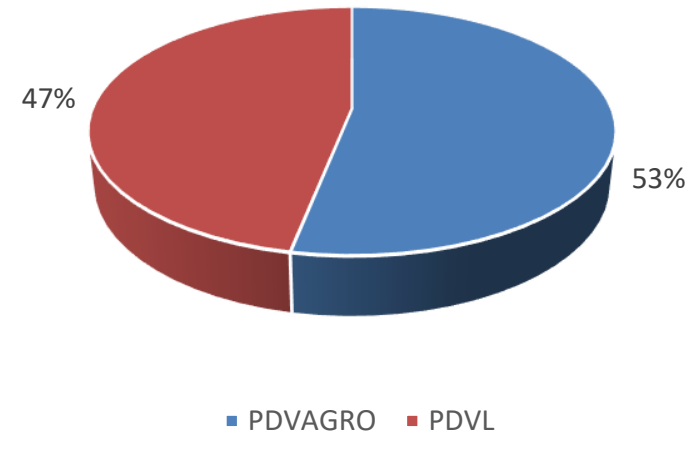

Fonte: Própria (2021) 
Gráfico 4: Cursos dos respondentes

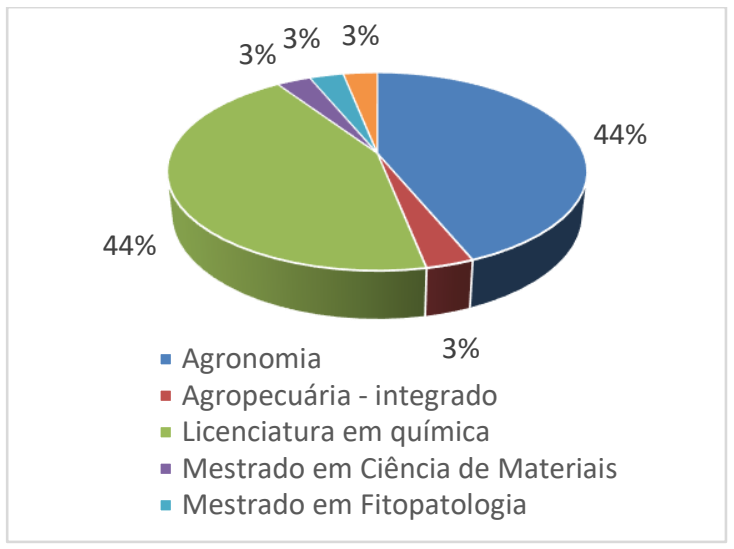

Fonte: Própria (2021)

Foram apresentadas frases que possuem relação com algumas das características empreendedoras identificadas por Dornelas (2008). As frases representam características como: ser dinâmico, inovador, proativo, líder, saber trabalhar em equipe. Como visto no Gráfico 5, há uma inclinação positiva ou de indiferença dos respondentes a essas qualidades citadas. Dornelas destaca tais qualidades como "características de um empreendedor de sucesso".

Grafico 5: Termos relacionados a características empreendedoras

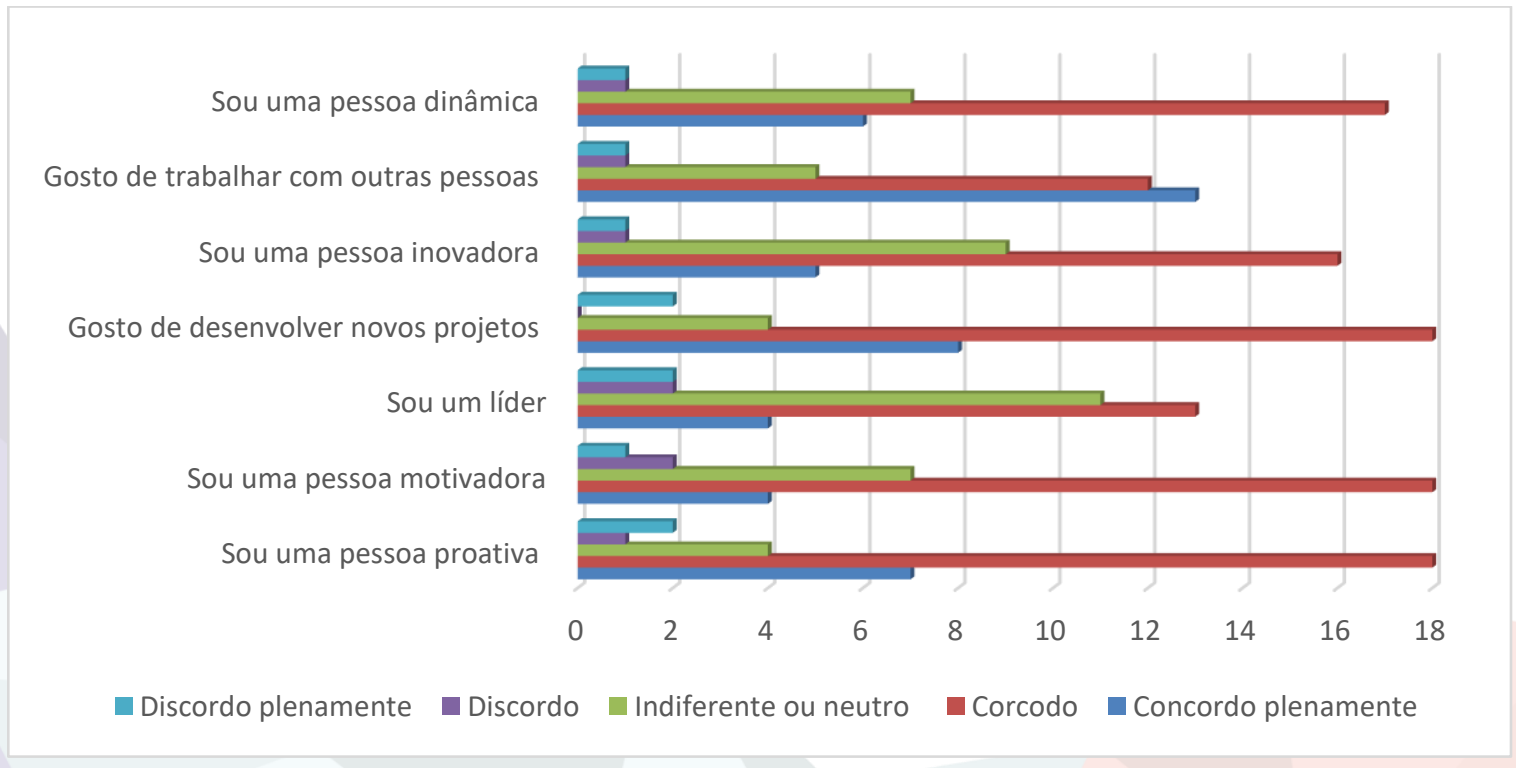

Fonte: Própria (2021)

Os resultados obtidos na escala Likert (Gráfico 5) fortalece o Gráfico 6 onde mostra que 86\% dos respondentes mostraram interesse em empreender em algum momento de suas vidas. Dornelas diz que o processo empreendedor pode ser aprendido e que o sucesso é decorrente de 
fatores internos e externos ao negócio, do perfil do empreendedor e de como ele administra as adversidades encontradas no seu dia a dia. Conforme o Gráfico 5, os respondentes demonstram ter as características do perfil empreendedor ou lhe são imperceptíveis causando indiferença, essa indiferença possivelmente é causada por $75 \%$ dos respondentes serem estudantes (Gráfico 7) que, como visto nos Gráficos 8 e 9, 59\% dos respondentes não participam ou participaram de ações voluntárias ou movimentos estudantis. Rabêllo (2004) fala da importância das interações sociais para o protagonismo. A indiferença apresentada no Gráfico 5, com seu pico maior em "ser líder" também pode estar relacionada a faixa etária dos respondentes (Gráfico 1) com $78 \%$ entre 17 e 24 anos.

Gráfico 6: Respondentes que já pensaram em empreender

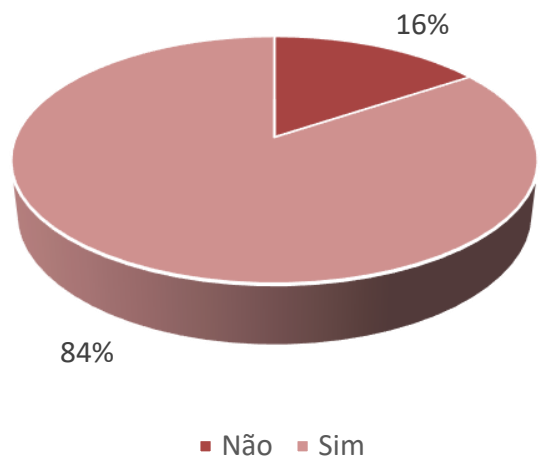

Fonte: Própria (2021)

Gráfico 9: Respondentes que já atuaram em movimentos estudantis (ex.: grêmios)

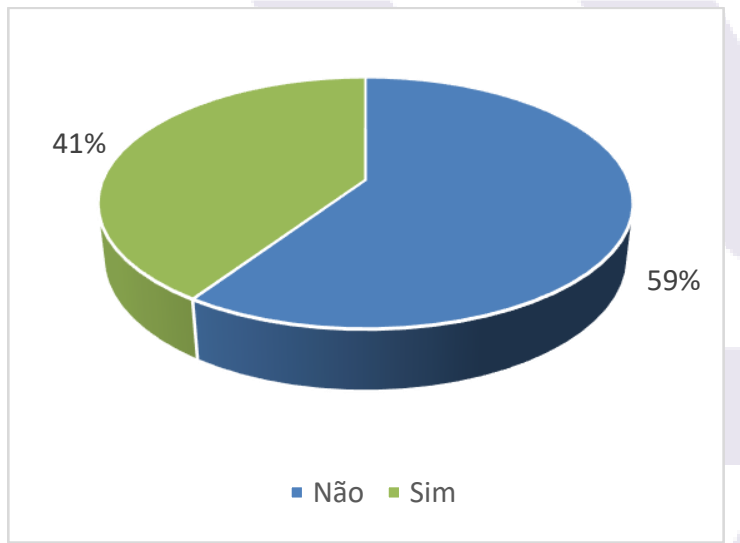

Fonte: Própria (2021)
Gráfico 7: Situação dos respondentes

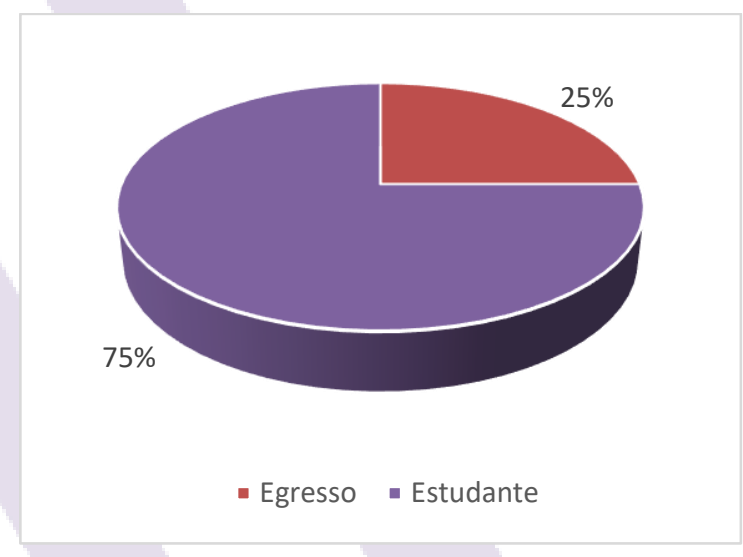

Fonte: Própria (2021)

Gráfico 8: Respondentes que atuaram em outras ações voluntarias.

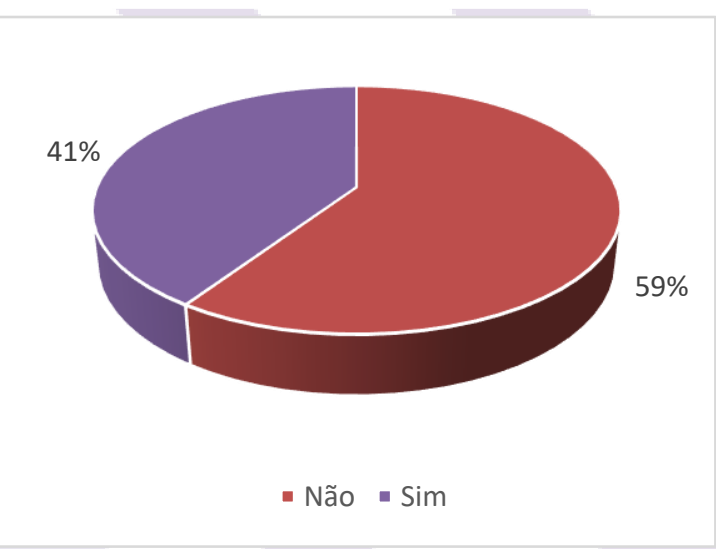

Fonte: Própria (2021)

É observada a consistência dos respondentes em permanecer no programa durante todo o período acadêmico do curso, 25\% dos participantes do questionário são egressos (Gráfico 7) 
tendo em sua maioria entrado no ano de 2016 (Gráfico 10) e atuado por 5 anos (Gráfico 11) isso se dá pelo tempo de duração da faculdade que é de 4 anos para licenciatura em química e 5 anos para agronomia. Essa continuidade é reforçada pelas palavras do quadro 1, onde percebese o impacto do PDV nas vidas dos participantes.

Gráfico 10: Ano de entrada dos egressos

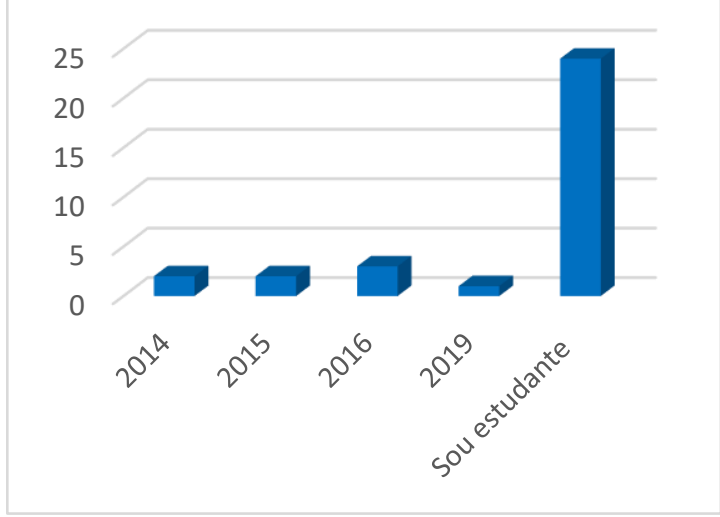

Fonte: Própria (2021)

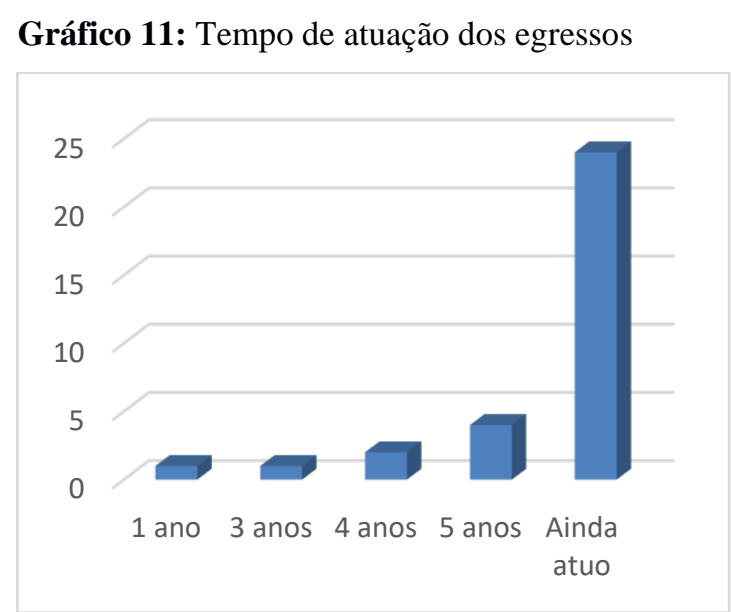

Fonte: Própria (2021)

Ser protagonista é atuar de forma incisiva nas ações, é ser autônomo e colaborar para mudanças sociais. Como citado por Dornelas (2008) nas "características do empreendedor de sucesso" os empreendedores de sucesso "são indivíduos que fazem a diferença, sabem tomar decisões, são independentes e constroem o próprio caminho, criam valor para a sociedade", o que denota que um empreendedor de sucesso é o protagonista. A atuação no programa desperta os respondentes ao protagonismo visto no Gráfico $12,50 \%$ dos respondentes se consideravam protagonistas antes da entrada no PDV, percebido nas respostas para a pergunta: Como você achava ser o PDV? Onde as palavras oportunidade e desenvolvimento apareceram em $45 \%$ (Gráfico 14) das frases a exemplo "Uma oportunidade para expandir meus conhecimentos." "Oportunidade de crescer como estudante e como profissional." "Desenvolver habilidades e liderança." Apresentando, assim um bom conhecimento prévio sobre o PDV e mostrando protagonismo ao buscar essas "oportunidades", não obstante a essa marcante presença do protagonismo houve um aumento para $88 \%$ dos participantes. 
Grafico 12: Respondentes que eram protagonistas antes de atuatem no PDV

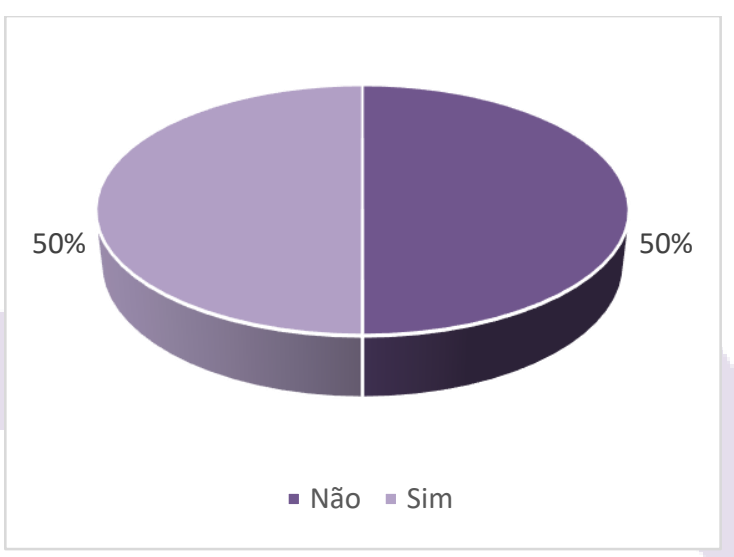

Fonte: Própria (2021)
Gráfico 13: Respondentes que se tornaram protagonistas após a participação no PDV

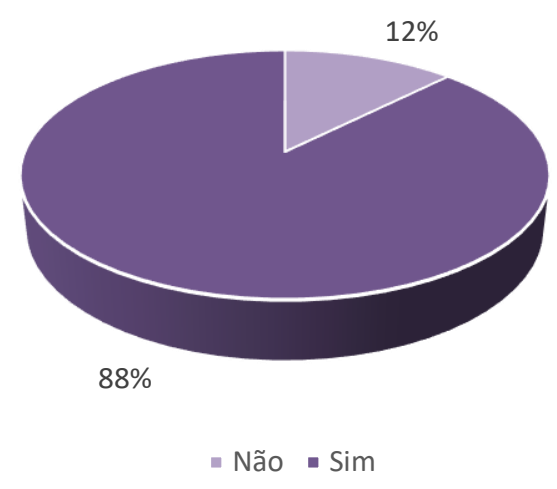

Fonte: Própria(2021)

Gráfico 14: Como você achava ser o PDV?

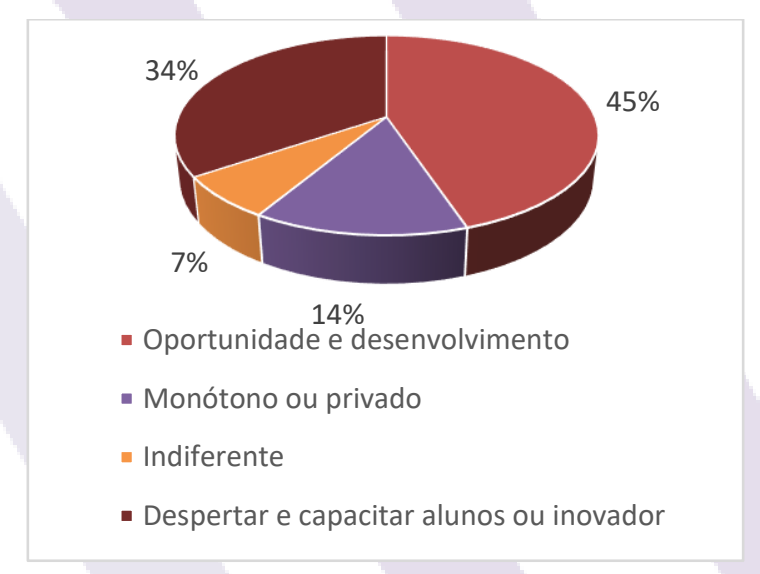

Fonte: Própria(2021)

No segundo momento do questionário foram feitas perguntas abordando a importância e o impacto que participar das ações do PDV tiveram em suas vidas. No Quadro 1 notamos palavras positivas sobre o impacto do PDV evidenciadas em motivação, superação, progresso, experiência, participação. Foi pedido para que os respondentes dissessem qual foi a diferença sentida em participar do PDV e se destacaram o incentivo ao protagonismo, o desenvolvimento pessoal, profissional e acadêmico, e a contribuição da interação social. Vistas em frases como "O PDV proporciona experiências que te coloca a frente de determinadas funções, facilitando o protagonismo." "Aprendi a ter um maior senso de responsabilidade e liderança, além de que quando entrei na faculdade, logo no primeiro período eu entrei no PDV, então muito do que aprendi sobre me soltar em sala de aula, produção científica, trabalhar em um grupo de estudos, desenvolver atividades, etc. eu aprendi no PDVL." "O PDV me abriu novos caminhos desde o 
particular ao profissional, me fez buscar sempre pelos meus objetivos, o quão importante é o trabalho em equipe e ao participar do PDV notei que é necessário a buscar pelo despertar dos jovens." "A forma como visualizo um problema e invisto meu tempo em resolvê-lo ao invés de buscar o que causou, de imediato." "Me tornei confiante e me senti capa de lutar pelos sonhos que considerava impossíveis.”.

Quadro 1: Definições dos respondentes quanto suas experiências no PDV

\begin{tabular}{|l|l|}
\hline & Revolucionário \\
& Crescimento \\
& Positivo \\
Esclarecedor & Habilidade \\
Gratidão \\
Excelente \\
em suas vidas, utilizando uma palavra & Impactante \\
Inovação \\
Progresso \\
Importância \\
Oportunidade \\
Superação \\
Gigantesco \\
Grandioso \\
Motivação \\
Inexplicável \\
Intenso \\
Experiência \\
Participação
\end{tabular}

Fonte: Própria (2021)

Os pilares do PVD incluem protagonismo estudantil, democratização do conhecimento, construção colaborativa, internacionalização e valorização profissional. Em conformidade com esses pilares, para analise foram feitas as perguntas: 1. Defina com participar do PDV ajudo no decorrer do curso. Bem como a pergunta: 2. Como atuar no PDV melhorou sua relação com o próximo? Na pergunta 1, podemos notar inclinação ao desenvolvimento do expressar-se em 
público o que ajuda na construção do network e expansão do saber não se limitando apenas ao que é ensinado no decorrer do curso. Observadas nas frases "Me ajudou a ficar menos nervosa ao falar em público e desenvolver melhor minhas habilidades a passar um conteúdo para outra pessoa." "Me ajudou na comunicação e nas experiências trocadas com veteranos." "Sempre buscando se relacionar mais com as pessoas, para aprender lidar e desenvolver novidades ou aprimorar o que já se atua de forma certa em certas comunidades." "Sair da zona de conforto para ampliação de novos horizontes voltados para, não só, a área de agronomia, mas para diversas áreas do conhecimento." "Ajudou em vários aspectos. Principalmente na minha desenvoltura em lidar com uma aula, turma e encarar novos desafios." "Consegui ter algo que no curso não é tão possível." "A abrir a mente para novas possibilidades." "Ajudou-me a ser um estudante protagonista." "Tive a oportunidade a madurecer bastante as minhas relações." "Não ter medo de participar."

Na pergunta 2 observamos que a atuação no programa ajuda no desenvolvimento de empatia e do senso de liderança que segundo Dornelas é uma das características de um empreendedor de sucesso, pois um líder respeita, valoriza, estimula, aqueles ao seu redor. Características vistas nas frases "Me fazendo assumir responsabilidades e entender um pouco da dinâmica de viver e trabalhar com pessoas." "Entender a realidade do próximo e ajustar-se para atender as necessidades de um conjunto e não mais, apenas individual." "Ajuda a ter empatia e saber se relacionar melhor com as pessoas e passar aquilo que está sendo proposto de uma forma legal e dinâmica." "Paciência e parceria para com os outros." "Ajudou bastante a entender melhor o outro" "Na forma de como lidar com certas situações, como lidar para conciliar faculdade, trabalho, dar aula e desenvolver artigos científicos." "Mais prestativo e auxiliador" "Aprendi a procurar formas distintas para diferentes tipos de pessoas, buscando sempre a melhor para cada um." "Em olhar o outro conforme as necessidades dele." "O trabalho em conjunto em prol de um mesmo objetivo."

Saber cooperar e ser proativo são, em resumo, as características essenciais para ter sucesso em ser empreendedor. Podemos ver pelas frases citadas que os respondentes seu lado empático e cooperativo após as atuações nos programas. Mostrando que trabalhar em equipe contribui para que o individuo se demonstre mais proativo como é notorio na fala de um dos respondentes: Me fazendo assumir responsabilidades e entender um pouco da dinâmica de viver e trabalhar com pessoas. Assim é possível perceber que participar do programa traz vantagens além da acadêmica.

\section{CONCLUSÕES}


O protagonismo juntamente ao empreendedorismo vem sendo discutido e incentivado nas últimas décadas. Estudos mostram que o protagonismo e empreendedorismo são “ensinados" ou "aflorado" ao individuo, sendo observadas por padrões socias comuns. Dornelas (2008) ressalta o despertar do empreendedor através das características de empreendedor de sucesso, mostrando que se houver empenho em ter tais características, qualquer pessoa poder ser um empreendedor de sucesso.

Com o objetivo de mapear e analisar os perfis dos protagnistas das ações do PDV, a pesquisa apresentou-se favoravel a hipótese de que o comportamento protagonista e empreendedor poder ser reforçado e até descoberto com a participação em programas voltados a ações extensionistas e de pesquisa.

O IIDV é norteado pelos princípios da democratização de conhecimento, construção colaborativa, protagonismo estudantil internacionalização, valorização da carreira profissional, e estes podem ser alavancados pelo desenvolvimento do Protagonismo e pela formação empreendedora, desenvolvida no âmbito do PDV. Com base na análise os dados obtidos, é notório que a atuação nos programas oferecidos no IIDV cumpre com o tratado acordado. Os participantes demonstram uma tendência a permanência durante todo o período acadêmico. A menção de palavras como protagonismo, cooperação, desenvolvimento, oportunidade, para classificar o programa e os impactos sentidos.

O protagonismo é incentivado em ambos os programas analisados, observados pelo aumento dos participantes que se consideram protagonistas antes e após a entrada nos programas do IIDV.

Esses dados demonstram que empreendedorismo não é algo inerentes ao sujeito desde o nascimento, como foi dinfundindo por tempos, e sim, algo aprendido, pois o protagonismo é a caraterística latente do empreendedorismo e com o incentivo e ensino é desenvolvido. A atuação em programas de pesquisa e extensão auxiliam no despertamento das características empreendedora dos protagonistas das ações.

\section{REFERÊNCIAS}

BRASIL, Sandra Aparecida, et. al. Empreendedorismo Jovem: Fatores que contribuem para a atividade empreendedora. Semana do administrador da Universidade Estadual de Maringá. Artigo.

Disponível em:http://periodicos.uem.br/ojs/index.php/CadAdm/article/view/22811/12314

CARVALHO, Maria do Carmo Nacif de, 2004. Gestão de pessoas. Rio de Janeiro: Senac nacional, 2014. 
DEBALD, B. S.; GOLFETO, N. V. Protagonismo Estudantil e Metodologias Ativas de Aprendizagem em Tempos de Transformação na Educação Superior. Foz do Iguaçu, PR: plêiade, 2016. Artigo. Disponível em: https://pleiade.uniamerica.br/index.php/pleiade/article/view/305/422

DEMO, P. e SILVA, R. A. Protagonismo estudantil. Marilia: Rev. ORG\&DEMO Unesp,2020.

DIMAGGIO, Paul J.; POWELL, Walter W. The iron cage revisited: Institutional isomorphism and collective rationality in organizational fields. American sociological review, p. 147-160, 1983.

DORNELAS, José Carlos Assis. Empreendedorismo: transformando ideias em negócios. Rio de Janeiro: Elsevier, 2008.

FREITAS, C. M. C. S. Escola e Universidade: encontros entre sociologia e educação [livro eletrônico] / organizadores Danyelle Nilin Gonçalves e Irapuan Peixoto Lima Filho. Fortaleza: Imprensa Universitária, 2020.

GEM -Global Entrepreneurship Monitor (2015). "O Empreendedorismo no Brasil. 2015.” Curitiba: IBPQ, 2015.

IFPE. Missão, Visão e Valores. Instituto Federal de Pernambuco - IFPE, 2016.

IIDV. Programa Internacional Despertando Vocações. / Coordenação geral Prof. MSc. Erick Viana da Silva. Recife, 2018.

LEITE, Emanuel, 1955. O fenômeno do empreendedorismo. São Paulo: Saraiva, 2012.

MARCEDO, Mariano de Matos, et. al. Global Entrepreneurship Monitor. Empreendedoridmo no Brasil: 2015/ coodernação de Simara Maria de Soua Silveira Greco. Curitiba: IBQP, 2014.

MARCIEL-BARBOSA, Tatiane Alves. Protagonismo do aluno e uso de metodologias ativas em prol da aprendizagem significativa a da educação humanista. Brasília: Rev. Educação, 2017.

SARKAR, Soumodip. Empreendedorismo e inovação. São Paulo: Escolar - $2^{\circ}$ edição, 2010.

RABÊLLO, M. E. D. L. O que é protagonismo juvenil. Acesso em, v. 5, 2004.

RODRIGUES, Jannyny de Oliveira Fogaça; DE CARVALHO, Sheyse Martins.

Evasão Feminina no Curso de Licenciatura em Física da UFT. In: WORKSHOP EM ENSINO DE FÍSICA DO TOCANTINS, 3, 2019. Tocantins. III Workshop em Ensino de Física do Tocantins [...]. Tocantins: UFT, 2019. 